paratively shallow downwarp of the Platformdesignated the Moscow 'syneclise'-extending from the Baltic Sea between Leningrad and Moscow and then turning sharply to the north. The unmetamorphosed Pre-Cambrian rocks which form the lowest part of the sedimentary cover of the Platform are called by Shatsky the Rhiphran Group. The transgression of the Cambrian over the latter can be traced all along the border of the Fennoscandian Shield ; thus the Rhiphæan is apparently equivalent to the Eocambrian or Sparagmitian of Norway. Shatsky even wishes to apply the term Rhiphæan to other similar deposits, such as the Sinian, found in China, Siberia, India and elsewhere; but in the absence of palæontological means of correlation, it is obvious that local names cannot yet be superseded. Shatsky's map shows the Rhiphæan-Lower Palæozoic syneclise (downwarp) separating the Baltic and Sarmatian Shields. The latter is divided by a narrow Rhiphæan trough into the Uralian-Volga massif on the north-east and the Kiev-Voronesh massif on the south-west.

\section{Synthetic Materials in Picture Conservation}

As important paper in the September issue of the Museums Journal, by Arthur Lucas and Norman Bromelle, of the National Gallery, London, deals with the failure of certain synthetic materials in picture conservation. They maintain that during the past few years a number of statements have appeared in the national and technical press which give the impression that newer materials discovered by the organic chemist are superior to the traditional varnishes, media and adhesives used hitherto. This paper has been written to warn restorers and conservators of the dangers incurred in accepting recommendations from partisans of the products of modern chemical industry. Mr. Lucas and Mr. Bromelle believe that modern synthetic materials have not fulfilled their promise for probably two reasons. First, the natural materials, glue, egg, natural resins, etc., are invariably complex in composition, each containing a large range of different substances often highly complex in themselves; in the process of forming, say, an adhesive bond, these different ingredients all play their part in reinforcing each other, so that in all the variations in surface properties of the parts to be attached the glue is sufficiently versatile to adapt itself. Secondly, a picture is composed of layers of wholly natural materials, apart from the pigments, and its response to external conditions (temperature, humidity, etc.) depends on the combined physical properties of these materials; the natural materials used in conservation can be made to harmonize readily with these properties, but the harmony is far more difficult with artificial materials. Full details of many of these new synthetic materials and their reactions are given in the paper quoted.

\section{The Musk-Ox}

FIRST recorded by an English youth so long ago as 1689 , the musk-ox forms the subject of an interesting article by $R$. Glover in a recent issue of $\operatorname{Oryx}(2$, No. 2). The musk-ox is a little-known Arctic mammal. Generally, these animals feed on moss but, when this is scarce, have been known to feed on the young twigs of willow, pine and even elm trees. They are gregarious, and each cow probably produces one calf every two years. One of the natural enemies of the musk-ox is the wolf; to resist attack by the latter, musk-oxen often stand, horns outward, in a bunch, practising a characteristic defensive drill. Apart from the use of the skin as warm robes, the animals have suffered little commercial exploitation by man and, although the musk-oxen have disappeared from wide areas they once inhabited, adequate stocks still remain. At present there are some prospects of domesticating the animal and this is causing some speculation in North America. Mr. Glover believes that the best way of making the musk-ox serviceable to mankind is not by domestication but by intelligent game management in its native home.

\section{The Philosophy of Numbers}

Is a communication to the Eleventh International Congress of Philosophy, held in Brussels during August 20-26, Prof. D. Riabouchinsky gave a summary of the ideas he has developed and published in a series of papers for forty years. His communication, which is entitled "La Définition des Nombres par leur Valeur numérique et par leur Origine; Rôle de ce Concept en Philosophie mathématique", is published in Vol. 5-Logic, Philosophical Analysis, Philosophy of Mathematics-of the proceedings of the Congress (Amsterdam: North Holland Publishing Co.; Louvain : Éditions E. Nauwelaerts, 1953). The ideas presented are so different from those usually held that they have been misunderstood or rejected without examination. The author does not consider two numbers as equal, even if they have the same numerical value, if they arise in a different manner: for example, sin $\pi / 2$ and $\sin 5 \pi / 2$, both of which have the numerical value $I$. Moreover, he distinguishes between Euclidean points, which are the extremities of lines, and dimensional points, which are the limits obtained by reducing to zero a length, surface or volume. The importance of this distinction is that it leads the author to reject certain well-known theorems in the theory of sets, such as Cantor's theorem that the number of points in a square is equal to the number in one of its edges. Another aspect of the author's point of view, and one more difficult to understand, is a theory of a new kind of imaginary numbers, which is associated with a principle attributed to Kant. He has also a generai theory of algebraic equations which contain the symbol for absolute value, but details are not given here.

\section{Research on Kilns in Japan}

Amovg the various topics discussed in Bulletin No. 60 of the Government Forest Experiment Station (Meguro, Tokyo ; March 1953) various aspects of the kilns used in Japan are considered. Experiments are being made with different types of charcoal kilns in four different provinces in Japan, and the methods of construction are outlined. Other experiments are connected with drying-kilns. Before the Second World War most of the kilns in Japan were of the natural ventilated type, its inadequacy being due to the impossibility of drying the boards evenly and quickly. After the War, the Sturtevant kiln was built, but its use in Japan has not apparently been satisfactory. The faults that have been discovered and the tests made on the kiln are all described in the bulletin.

Indian National Scientific Documentation Centre : Report for the Year 1952-53

The first annual report, for the year 1952-53, of the Indian National Scientific Documentation Centre 